\title{
Implicações psicossociais da seca na vida de moradores de um município da zona rural do nordeste do Brasil
}

\section{Drought Implications in the Lives of Residents of the Rural Mortheast \\ Consecuencias de la sequía en la vida de los residentes del noreste rural de Brasil}

\author{
Carla Evelline de Sousa Camurça, ${ }^{*}$ Alana Braga Alencar, Elívia Camurça Cidade," \\ Verônica Morais Ximenes* \\ Universidade Federal do Ceará, Brasil.
}

Doi: dx.doi.org/10.12804/ap134.1.2016.08

\section{Resumo}

A seca é um fenômeno natural e físico que ocorre com certa regularidade no Nordeste do Brasil. A compreensão reducionista desta problemática, associada à falta de água, facilita a naturalização de seus efeitos sociais. O artigo objetiva discutir as implicações psicossociais da seca na vida de moradores de uma comunidade rural do nordeste do Brasil. A metodologia foi quantitativa, com a aplicação de um questionário com 207 sujeitos, moradores da Comunidade da Canafístula, município do estado do Ceará. Obteve-se que $87.9 \%$ dos participantes passaram por alguma seca, o que impactou na falta de água para o consumo humano e animal, nas perdas na produção. A insegurança quanto ao futuro, sentimentos de desânimo e tristeza, fatalismo e desesperança apreendida aparecem como implicações psicossociais da seca. Destaca-se a importância da desnaturalização deste fenômeno e da análise dos seus impactos objetivos e subjetivos na vida das comunidades rurais.

Palavras chave: seca; comunidade rural; psicologia.

\section{Abstract}

Drought is a natural and physical phenomenon that occurs with some regularity in the Northeast of Brazil. The reductionist understanding of this problem, associated with lack of water, facilitates the naturalization of its social effects. The article aims to discuss the psychosocial impacts of the drought in the lives of residents of a rural community in northeastern Brazil. The methodology is quantitative, with the provision of a questionnaire to 207 subjects, residents of Canafístula Community, city of the State of Ceará. It was learned that $87.9 \%$ of participants had lived through some drought, which impacted on the lack of water for human and animal consumption, in production losses.

* Carla Evelline de Sousa Camurça, mestre em Psicologia pela Universidade Federal do Ceará, Brasil; Alana Braga Alencar, mestre em Psicologia pela Universidade Federal do Ceará. Professora temporária da Universidade Estadual do Ceará; Elívia Camurça Cidade, doutoranda em Psicologia da Universidade Federal do Ceará, bolsista da Fundação Cearense de Apoio ao Desenvolvimento Científico e Tecnológico; Verônica Morais Ximenes, doutora em Psicologia pela Universidade de Barcelona, professora da Graduação e Pós-Graduação da Universidade Federal do Ceará.

A correspondência deste artigo pode se dirigir a Carla Evelline de Sousa Camurça. Correio eletrônico: carlaevelline@hotmail.com

Como citar este artigo: Camurça, C. E., Alencar, A., Cidade, E. \& Ximenes, V. (2016). Implicações psicossociais da seca na vida de moradores de um município da zona rural do nordeste do Brasil. Avances en Psicología Latinoamericana, 34(1), 117-128. doi: dx.doi.org/10.12804/ap134.1.2016.08 
Insecurity about the future, feelings of discouragement and sadness, fatalism and acquired hopelessness appear as psychosocial impacts of the drought. It highlights the importance of denaturalization of this phenomenon and the analysis of the objective and subjective impacts on the lives of rural communities.

Keywords: drought; rural community; psychology.

\section{Resumen}

La sequía es un fenómeno natural y físico que se da con cierta regularidad en el nordeste de Brasil. La visión reduccionista de esta problemática, asociada con la falta de agua, facilita la naturalización de sus efectos sociales. El artículo tiene como objetivo discutir las implicaciones psicosociales de la sequía en la vida de los habitantes de una comunidad rural del nordeste de Brasil. La metodología fue cuantitativa, con la aplicación de un cuestionario con 207 sujetos, habitantes de la comunidad de Canafístula, municipio del estado de Ceará. Se obtuvo que el $87.9 \%$ de los participantes había pasado por alguna sequía, lo que impactó en la falta de agua para el consumo humano y animal, así como en las pérdidas en la producción. La inseguridad respecto al futuro, sentimientos de desánimo y tristeza, fatalismo y desesperanza aprehendida se analizaron como implicaciones psicosociales de la sequía. Se destaca la importancia de la desnaturalización de este fenómeno y del análisis de sus impactos objetivos y subjetivos en la vida de las comunidades rurales.

Palabras clave: sequía; comunidad rural; psicología.

Depois de se benzer e de beijar duas vezes a medalhinha de São José, dona Inácia concluiu:

"Dignai-vos ouvir nossas súplicas, ó castíssimo esposo da Virgem Maria, e alcançai o que rogamos. Amém."

Vendo a avó sair do quarto do santuário, Conceição, que fazia as tranças sentada numa rede ao canto da sala, interpelou-a: - E nem chove, hein, Mãe Nácia? Já chegou o fim do mês... Nem por você fazer tanta novena... Raquel de Queiroz (2008, p. 11)
Nos escritos de Raquel de Queiroz encontramos o relato da seca, do sertão que arde diante da ausência da chuva nos anos de 1915. Quase cem anos depois, este fenômeno climático que forja uma realidade ecológico-sócio-política (Matos, 2012) continua a interferir nos modos de organização da população nordestina ao contribuir com o ciclo da seca e o agravamento da desigualdade social. Afinal, desde o ano de 2013, a região do semiárido nordestino vem sendo palco da maior seca dos últimos 50 anos (Organização das Nações Unidas no Brasil, 2013).

A vida no semiárido nordestino é historicamente marcada, no tempo e no espaço, por histórias que revelam resistência e luta no enfrentamento da pobreza rural e pela busca da democratização do acesso à terra e à água. As relações sociais que se expressam são marcadas por intermédio do poder dominante das classes conservadoras e do patriarcalismo. A política assume uma posição centrada no clientelismo. A vivência com o fenômeno natural da seca e seus impactos no modo de vida; a desigualdade social, a exclusão e a pobreza; as políticas públicas de desenvolvimento rural que amenizam a situação vulnerabilidade social, porém não retira as pessoas da situação de pobreza.

Este artigo objetiva discutir as implicações psicossociais da seca na vida de moradores da comunidade rural da Canafístula, interior do Ceará. Considera-se que a redução acentuada dos índices de chuva, associada às políticas deficitárias de convivência com a seca e ao histórico processo de desigualdade social observados na região Nordeste, contribuem para o aumento das consequências deste fenômeno.

A seca é um fenômeno natural e físico que ocorre com certa regularidade no Nordeste. Pode se repetir de 8 a 10 vezes em um século e chega a estender-se por até cinco anos, causando problemas de natureza social e política (Duarte, 1999). Nesse sentido, tem-se que a seca é natural, posto que se dá em decorrência da própria localização geográfica nordestina, mas seus impactos nocivos 
na vida da população não o são. Ao contrário, são as relações sociais, econômicas e políticas dela decorrentes que favorecem a sua naturalização ao permitir a perpetuação de modos de interação fundamentados nos favorecimentos políticos e na submissão financeira e ideológica.

A associação da seca à falta de água fez com que durante longo período a solução política elaborada se desse através da construção de grandes obras para acúmulo de recursos hídricos, das quais poucos proprietários (os ricos) tinham o privilégio e eram favorecidos em suas propriedades, utilizando recursos públicos oferecido pelo governo. Essas ações foram conhecidas como a indústria da seca (Nobre, 2010, p. 7). Afinal, era a alta concentração de verbas federais nas mãos da elite regional conservadora o elemento que garantia a perpetuação da pobreza na região do semiárido nordestino. Tal constatação permite a crítica ao determinismo intelectual que estabelece uma relação direta entre clima e pobreza (Ribeiro, 1999).

É bem verdade, o que ocorre é que, no contexto rural, a seca acentua "as desigualdades em todos os níveis (social, racial, sexual, etário, regional, internacional, etc.)" (Matos, 2012, p. 3), contribuindo para o agravo de suas consequências na vida das comunidades rurais. Expressos no cotidiano das áreas rurais, os impactos da seca incidem nas perdas na agricultura e na pecuária, fazendo com que haja a exposição dos moradores a um elevado nível de estresse, chegando a afetar a saúde desses sujeitos ao submeter-lhes a um cotidiano de incertezas e indefinições.

Afirma-se, diante deste cenário, as contribuições possíveis da Psicologia para a análise e proposição de ações junto às comunidades rurais que enfrentam as consequências psicossociais da seca. Entretanto, é preciso que seja também colocada em discussão a constituição da Psicologia como campo de saber ideologicamente situado no contexto urbano, permanecendo distante da realidade rural e de suas problemáticas e potencialidades (Leite, Macedo, Dimenstein \& Dantas, 2013). Buscando compreen- der os sujeitos na relação consigo, com os outros e com o ambiente em que vivem e convivem, a Psicologia tem muito a contribuir através de estudos teóricos e metodológicos voltados aos sujeitos de uma coletividade que vivencia situações adversas de vulnerabilidade social, como é o caso da seca.

Outro fator que justifica a importância de se pensar as implicações psicossociais da seca em contexto rural diz respeito à crescente interiorização da profissão, que tem se deslocado dos grandes centros urbanos para atuar em contextos rurais, muitas vezes sem a reflexão necessária (Leite, Macedo, Dimenstein \& Dantas, 2013). Com isso, acredita-se que esta pesquisa poderá fornecer subsídios para a formulação de intervenções junto às populações rurais e que sejam condizentes com as suas necessidades.

\section{Cenários da seca no nordeste}

O nordeste brasileiro é denominado como região semiárida. Possui nove estados e ocupa uma área de $1.219 .000 \mathrm{~km}^{2}$. Segundo a Lei $175 \mathrm{de} \mathrm{ja-}$ neiro de 1936, esta região ficou conhecida como Polígono das Secas, caracterizada pelo clima semiárido, pelas chuvas concentradas entres os meses de fevereiro e maio, pela vegetação de caatinga e pela existência de secas periódicas que desafiam a capacidade humana de sobreviver e produzir.

Santos, Matos, Alvarenga e Sales (2012) referem que há a dificuldade de estabelecimento de uma definição da seca que seria comum ao nordeste brasileiro. É preciso que se considerem as percepções de cada sujeito e de sua realidade, embora seja possível a compreensão de que, no universo do senso comum, a palavra seca esteja recorrentemente associada à penúria, à fome, à terra ressequida com a vegetação sem vida, aos carros pipas, ${ }^{1}$ aos animais deflagrados e ao retirante

1 Carros pipas ou caminhão-pipa são meios de transporte utilizados para o abastecimento de água potável em residências, indústrias, condomínios dentre outros locais. Em regiões onde há seca, este tipo de fornecimento de água é custeado com recursos governamentais e/ou privados. 
fugindo da terra natal e/ou do preguiçoso que suga verbas do governo.

Desde o período colonial até os dias atuais, o fenômeno da seca aparece como um dos responsáveis pelos problemas sociais na região Nordeste. A compreensão reducionista desta problemática associada à falta de água facilita a aceitação das consequências da seca como problemas naturais. Castro refere que a seca tornou-se uma vilã do drama nordestino, em que a principal imagem que se tem desta região é de "uma terra estorricada, amaldiçoada, esquecida de Deus" (1967, p. 168). Os sentimentos decorrentes da falta de controle sobre a natureza favorecem a associação da seca como sendo um acontecimento independente da ação humana e sim fruto da vontade divina. Com isso, o sofrimento oriundo da escassez de água faz o povo nordestino suplicar a Deus por chuva, vinculando a seca à religiosidade, que é um elemento presente na vida dos nordestinos (Vieira, 2003).

Percebe-se que o fenômeno da seca perpetua sentimentos de impotência de geração em geração, fazendo desse fenômeno um dos grandes responsáveis pela naturalização da miséria, da pobreza e da desigualdade social. Contudo, embora haja uma perspectiva de permanência do ciclo periódico da seca, o que assegura sua definição como processo natural, o grande desafio que se coloca é a desnaturalização deste fenômeno e a percepção de que é possível conhecer esse processo e empreender ações para diminuir suas consequências danosas. Compreender a seca como um acontecimento natural, nesse sentido, deveria implicar na ampliação de esforços eficazes e eficientes para sua superação de maneira adequada, minimizando ou anulando seus riscos à integridade socioeconômica e psicológica dos sujeitos.

Segundo Ribeiro (1999), a aproximação da geografia com as ciências naturais fez com que o determinismo da natureza explicasse as manifestações de ordem geográfica sobre as populações através de uma causa natural. O determinismo geográfico nordestino fundamenta o discurso da seca e a as- sociação de que a natureza é a única responsável pela miséria que atinge esta região. Esse discurso exerce um poder sobre a população e justifica os impactos sociais através de acontecimentos regidos por leis implacáveis e que sempre irão se repetir, sem que nada possa ser feito. Carvalho (1988) e Castro (1992) mostram que o discurso sobre a naturalização dos problemas sociais causados pela seca está ligado a estratégias das oligarquias regionais na manutenção do poder e da riqueza.

O determinismo geográfico e a naturalização do fenômeno da seca se configuram também como fatores de ordem simbólica e ideológica que a ela confere um caráter de cotidianidade atemporal. Diante do risco da naturalização dos fenômenos sociais que perpetuam a pobreza e a desigualdade social, Martín-Baró (1998) coloca-nos a necessidade de desideologizar as experiências do cotidiano a partir da recuperação da memória histórica coletiva, que pode favorecer a ampliação da consciência e da compreensão dos nexos causais envoltos na manutenção da seca como problemática que leva ao agravo das questões sociais. Assim, compreender historicamente o processo da seca no nordeste é imprescindível para a superação dos determinismos e das cadeias de naturalizações dela decorrentes.

Para Andrade, é necessário “[...] desmistificar a ideia de que a seca, sendo um fenômeno natural, é responsável pela fome e pela miséria que dominam na região" (1985, p. 7). A questão da seca não é a falta de água, o que falta é sua divisão correta. Ao apreender a dimensão histórica das condições de vida dos moradores e das diversidades rurais do semiárido nordestino, reconhecemos que a região Nordeste é marcada pela desigualdade, exclusão social e pobreza desde o período colonial até os dias de hoje, assim como o fenômeno natural da seca não é o único responsável por essa realidade.

Carvalho (2012) traz a ideia de seca social e apresenta sua interferência sobre os aspectos sociais, econômicos, institucionais e políticos. Os aspectos sociais afetam as pessoas com relação à saúde, educação, emprego e migrações; os econômicos refe- 
rem-se aos prejuízos causados sobre a economia em geral; os institucionais relacionam as mudanças das instituições públicas que executam programas de convivência com a seca; os políticos dizem respeito às consequências que o fenômeno da seca traz sobre os processos decisórios que os agentes públicos e privados encontram como forma e procedimentos para enfrentar os problemas relacionados à seca; e ambientais, têm relação com as alterações que a seca provoca no meio ambiente em geral.

O Censo do Instituto Brasileiro de Geografia e Estatística (Instituto Brasileiro de Geografia e Estatística, 2011) apresentou dados de que no Brasil existem 16,2 milhões de pessoas vivendo em extrema pobreza e que $59 \%$ destas pessoas estão na região do Nordeste, sendo $52 \%$ destes vivendo em extrema pobreza na zona rural. Com a escassez das chuvas, os trabalhadores e as famílias sofrem penosamente com os fenômenos sociais da fome, da sede, da desnutrição, da miséria, da pobreza, do desemprego, da falta de oportunidades, da desigualdade social e/ou da migração para os centros urbanos em busca de sobrevivência.

Frente a este cenário, Echeverria (1998) e Mocelin (2011) tomam como características da pobreza rural: nutrição insuficiente, problemas de saúde e educação deficiente, oportunidades escassas de emprego nas atividades agrícolas e não agrícolas, baixo grau de organização para promover efetivamente os interesses rurais, dificuldade de acesso às políticas públicas e a não assistência das organizações de extensão rural. Além disso, cerca de $70 \%$ da renda total familiar é proveniente do cultivo e do trabalho agrícola (Banco Mundial, 2001). Temos então que o fenômeno da seca vai impactar negativamente também na capacidade de subsistência da população e na geração de emprego e renda, que dependem das condições climáticas favoráveis para produzir na agricultura.

$\mathrm{Na}$ atualidade, ações governamentais vêm sendo efetivadas para o enfrentamento da seca. Com o objetivo de reforçar a rede de proteção social no semiárido, em abril de 2013, o Governo Fede- ral investiu em medidas de convivência com as secas, em que foram criados programas sociais de transferência de renda, que amenizam o sofrimento das famílias e dos produtores rurais. Entre as ações emergenciais estão: operação carro-pipa, construção de cisternas, perfuração e recuperação de poços, bolsa estiagem, venda de milho, programa garantia-safra e ampliação da linha de crédito emergencial, assim como renegociação de dívidas (Brasil, 2013).

Essas ações das políticas públicas minimizam por curto tempo a falta de água, porém não modificam a estrutura socioeconômica e política, assim como a situação de quem mais sofre com esse problema, a população rural, e amenizam a fome sem amenizar a vulnerabilidade social e sem retirar as pessoas da condição de miséria. Afinal, é preciso se ter em mente que a pobreza na região rural do nordeste brasileiro faz parte de uma realidade persistente de desigualdades na posse de terras, nas políticas públicas que nem sempre chegam a todas as comunidades rurais, na instabilidade no trabalho e nas condições climáticas que acarretam agravamentos psicossociais.

Nesta perspectiva, é relevante abordar não mais a noção de combate à seca ou de luta contra este fenômeno climático. Trata-se, na atualidade, da busca por estratégias de convivência com ela. Porém, para que este intuito seja alcançado, é preciso o conhecimento de que os impactos da seca são materiais e imateriais, objetivos e subjetivos. Tem-se, dessa forma, que a análise da seca, enquanto problema social e histórico, permite a consideração de que suas implicações incidem na vulnerabilidade social vivenciada pelas pessoas, nas atividades econômicas que realizam, no contato que estabelecem com o ambiente, nos modos de vida, assim como, na vivência de processos de saúde e adoecimento e no bem-estar da população. Com isso, ratifica-se a relevância do intuito desta pesquisa que é discutir as implicações psicossociais da seca na vida de moradores da comunidade rural da Canafístula, interior do Ceará. 


\section{Metodologia}

A pesquisa foi realizada junto aos moradores de Canafístula, localidade rural distante 26 quilômetros da cidade de Apuiarés (Ceará), que é sua sede. Canafístula está situada a 118 quilômetros de Fortaleza. Caracteriza-se por ser uma comunidade do sertão cearense na qual vivem cerca de 170 famílias, contabilizando pouco mais de 1000 pessoas (Gomes, 2010).

O distrito possui equipamentos sociais, tais como escolas de ensino fundamental e médio, Posto de Saúde com equipe da Estratégia de Saúde da Família, espaços para prática de esportes, correio e alguns comércios de pequeno porte. A renda local provém da agricultura familiar, benefícios sociais, funcionalismo público e aposentadorias. De acordo com Gomes (2010), Canafístula vem se projetando economicamente através da criação de caprinos e ovinos. Com o intuito de fortalecer a produção familiar local, em 1987 foi fundada a Associação dos Agricultores da Canafístula, composta pelo conjunto de sete lugarejos da região.

A amostra foi composta por 207 moradores, sendo 121 mulheres, 74 homens e 12 pessoas não especificaram (missing). Os dados sociodemográfi$\cos$ da população pesquisada mostram que do total da amostra, $62.1 \%$ eram casados ou moravam com um(a) companheiro(a) e $28.2 \%$ eram solteiros. A quantidade média de filhos por pessoa entrevistada era 3.16, sendo a média de quantidade de pessoas por domicílio 4.07. As idades variavam de 18 a 88 anos, sendo a média de idades estabelecida em 42 anos.

Em termos de religião, 89.7\% eram católicos e $6.4 \%$ protestantes ou evangélicos. Tem-se também que $65.4 \%$ dos entrevistados eram beneficiários de algum programa de transferência de renda (bolsa família e outros). Quanto à educação, embora 30\% dos entrevistados tivessem estudado por 12 anos ou mais (ensino médio completo ou ensino superior), $30.9 \%$ estudou até 5 anos (ensino fundamental incompleto) e $13.5 \%$ não estudou. Quanto à ren- da familiar, $56.5 \%$ somavam entre 1 e 2 salários mínimos e $27.1 \%$ somavam menos de um salário mínimo. Durante a construção da pesquisa, $62.8 \%$ não estava exercendo algum tipo de trabalho remunerado. Em relação à política pública de saúde, $43 \%$ responderam que poucas vezes conseguiam atendimento médico ou de outros profissionais de saúde quando precisam.

O Questionário de Influências da Seca, adaptado a partir de um conjunto de itens utilizados para descrever a experiência da seca por Favero (2012), foi adotado como instrumento de obtenção de dados. Esse Questionário é composto por 11 perguntas em relação às consequências da seca na vida familiar dos agricultores. Os dados coletados foram organizados e analisados em uma base de dados no pacote estatístico SPSS 20.0. A pesquisa foi submetida ao Comitê de Ética em Pesquisa da Universidade Federal do Ceará, por meio de sistema da Plataforma Brasil e foi aprovado com CAAE: 07810512.3.0000.5054 e Parecer 191.508.

\section{Implicações psicossociais da seca na comunidade da Canafístula}

A vida em situação de seca reverbera em diversas implicações políticas, econômicas, culturais e sociais que afetam o nordeste brasileiro. Os aspectos psicossociais são dizem respeito ao modo como as condições concretas de vida se vinculam a constituição das ideias, dos pensamentos e dos sentimentos desenvolvidos nos contextos de vida em que coexistem a seca e a pobreza. Na tabela 1 , dentre as 207 pessoas entrevistadas, 175 pessoas $(87.9 \%)$ vivenciaram diretamente a seca ou tiveram familiares que experienciaram esta situação.

A incidência positiva de seca junto a $87.9 \%$ dos participantes da pesquisa ratifica a afirmação de Favero (2012) de que as comunidades rurais são as mais vulneráveis aos impactos psicossociais deste fenômeno posto que dependem economicamente dos recursos naturais para o desempenho de suas práticas produtivas. Observou-se que 63.4\% 
Tabela 1

Análise dos dados frequência seca*

\begin{tabular}{lcccccc}
\hline & \multicolumn{2}{c}{ Sim } & \multicolumn{2}{c}{ Não } & \multicolumn{2}{c}{ Total } \\
\cline { 2 - 6 } & $\mathrm{F}$ & $\% *$ & $\mathrm{~F}$ & $\%$ & $\mathrm{~F}$ \\
\hline $\begin{array}{l}\text { 2. Sua família ne- } \\
\text { cessitou em algum } \\
\text { momento modificar } \\
\text { planos ou projetos } \\
\text { em função de uma } \\
\text { seca? }\end{array}$ & 111 & 63.4 & 64 & 36.6 & 175 \\
\hline
\end{tabular}

3. Sua família se encontrou em algum

$\begin{array}{llllll}\text { momento endivida- } & 81 & 46.6 & 93 & 53.4 & 174\end{array}$

da como consequên-

cia da seca?

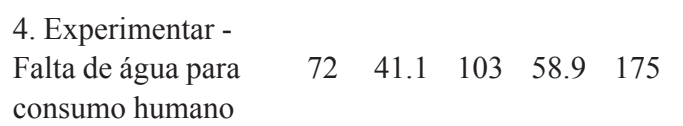

\begin{tabular}{lccccc}
\hline $\begin{array}{l}\text { 5. Experimentar - } \\
\begin{array}{l}\text { Falta de água para } \\
\text { consumo animal }\end{array}\end{array}$ & 95 & 45.9 & 80 & 45.7 & 175 \\
\hline $\begin{array}{l}\text { 6. Experimentar - } \\
\text { Perdas na produção }\end{array}$ & 163 & 93.1 & 12 & 6.9 & 175 \\
\hline
\end{tabular}

7. Experimentar -

$\begin{array}{llllll}\text { Insegurança quanto } & 138 & 79.3 & 36 & 20.7 & 174\end{array}$

ao futuro

8. Experimentar

- Sentimentos de $\quad \begin{array}{lllll}144 & 82.8 & 30 & 17.2 & 174\end{array}$

desânimo e tristeza

9. Experimentar

$\begin{array}{llllll}\text { - Dificuldades rela- } \quad 75 & 42.9 & 100 & 57.1 & 175\end{array}$

cionadas ao sono

10. Saída do campo

para a cidade de

algum membro da

$\begin{array}{lllll}68 & 32.9 & 106 & 60.9 & 174\end{array}$

família

11. Saída de algum

membro da família $\quad \begin{array}{lllll}23 & 13.1 & 152 & 86.9 & 175\end{array}$

da escola

* Para elaboração desta tabela foi considerado apenas o percentual válido.

Fonte: elaboração propria.

dos participantes necessitaram, em decorrência da experiência de seca, modificar planos ou projetos. A incerteza decorrente da seca traz como consequência a exposição dos sujeitos a situações estressoras que podem vir a afetar a saúde psicológica. A indefinição quanto ao futuro, uma vez sendo perpetuadas ao longo do tempo, favorecem o desenvolvimento do estresse continuado ou crônico (Góis, 2008) ao submeter o sujeito às condições de instabilidade financeira e emocional. Afinal, é preciso destacar que estas mudanças de planos se devem, em grande parte das ocasiões, às perdas da produção que podem levar ao endividamento e a alimentação de um ciclo de manutenção da pobreza.

$\mathrm{O}$ alto índice de perdas da produção agrícola junto aos entrevistados, contabilizando $93.1 \%$, indica que, mesmo ocorrendo certo empenho para a criação de infraestruturas capazes de disponibilizar água suficiente para garantir o abastecimento humano e animal e viabilizar a irrigação, estes esforços ainda são insuficientes para dar conta das problemáticas decorrentes da escassez de água (Cirilo, Montenegro \& Campos, 2007). Interessante perceber que, dentre os 163 sujeitos que tiveram perdas na produção, 79 sujeitos $(48.8 \%)$ se encontraram em situação de endividamento. Tal dado permite inferir que, se as políticas de combate à escassez de água ainda tem se demonstrado insuficientes, são as ações de redistribuição de renda que têm minimizado os impactos monetários da seca na vida da população rural.

Em âmbito nacional, as políticas de transferência de renda se configuram como ações públicas estatais com o intuito de diminuir a alta concentração de bens monetários característica do modelo econômico brasileiro (Marinho, Linhares \& Campelo, 2011). A criação no ano de 2004 do Programa Bolsa Família, mediante a integração de ações transferenciais como Bolsa Escola e Vale Gás e, posteriormente, em 2011, a formulação do Plano Brasil sem Miséria, através do Decreto 7.492 (Brasil, 2011), são ações governamentais ancoradas no intuito de elevar a renda familiar per capta e melhorar as condições de vida da população. 
Considerar a multidimensionalidade da situação de pobreza, tal como proposto na Abordagem das Capacitações de Amartya Sen (2000), implica a ampliação da noção de pobreza como privação monetária e afirma as dimensões de saúde, educação, habitação, lazer, segurança e padrão de vida como indicadores de análise da incidência de pobreza. Todo ser humano é concebido como dotado de um potencial ativo de transformação da sociedade, porém há elementos que intervém de modo a limitar o exercício destas potencialidades e as vivências de bem-estar dos sujeitos. A pobreza, nesse sentido, interfere nas capacitações do sujeito de exercer seus funcionamentos, que são relativos ao que a pessoa pode fazer e ao que a pessoa pode ser em diferentes dimensões da vida (Alkire, 2005; Sen, 2000). Caberia, porém, ao Estado e a sociedade o compromisso social para o fortalecimento e a proteção das capacitações humanas (Sen, 2000).

Conforme apontam os estudos de Duarte, Sampaio e Sampaio (2009), o Programa Bolsa Família acarreta uma interferência positiva direta no aumento de gasto das famílias rurais com a compra de alimentos. Os benefícios monetários concedidos diminuem o impacto da fome decorrente da perda da produção agrícola e minimizam o endividamento das famílias. Contudo, isto não quer dizer que as consequências sociais e econômicas decorrentes da seca sejam plenamente sanadas.

Outro indicador de que as ações públicas destinadas ao enfrentamento das consequências negativas da seca são não plenamente eficazes diz respeito às experiências de falta de água para o consumo humano (41.1\%) e para o consumo animal (54.3\%). A falta de água adequada para o consumo humano, como recurso básico para a vida, impacta diretamente na saúde fisiológica e psíquica dos moradores da zona rural de todas as faixas etárias, assim como a falta de água para o consumo dos animais impacta na morte de rebanhos, o que representa um dos fatores para o endividamento. Segundo Bruna e Pisane (2010), as mudanças climáticas acentuam a situação de pobreza à medida que são as populações pobres aquelas mais vulneráveis aos riscos decorrentes dos acidentes naturais, fazendo com que seus impactos sejam ainda mais danosos caso não haja planejamento. No que concerne aos impactos psicológicos, destaca-se a interferência do fenômeno da seca para as experiências vividas de insegurança quanto ao futuro e de sentimentos de desânimo e tristeza. Entre os pesquisados, 79.3\% afirmaram ter experimentado insegurança quanto a projetos futuros, ao passo que $82.8 \%$ disseram ter experimentado desânimo e tristeza em decorrência de situações de seca. Tais dados apontam para as relações existentes entre a seca, a pobreza e o agravamento das implicações psicossociais decorrentes destes fenômenos.

É importante situar que o termo psicossocial é por nós entendido a partir da apropriação do materialismo histórico dialético e significa uma síntese das dimensões psicológica e social, simbólica e material, compreendendo que ambas se relacionam intrinsecamente incidindo em processos de desenvolvimento mútuo do sujeito e do seu entorno social (Vygotsky, 1991).

Pode-se afirmar que a seca, assim como a pobreza, acarreta implicações sociais (acesso à renda, às políticas públicas, às condições adequadas de vida), objetivas (no ambiente, na economia, na política, na cultura e na história comunitária) e psicológicas (modos de pensar, agir e sentir). A proximidade entre estes dois fenômenos está no fato de que ambos somente têm suas consequências amplificadas em função de interesses ideológicos existentes na manutenção da submissão e da conformação que alimentam. Manter o sujeito na pobreza e submetê-lo às instabilidades decorrentes da seca favorece a perpetuação da opressão.

Para Cidade, Moura Junior e Ximenes (2012), em uma sociedade onde a pobreza impera, existem formas singulares de estruturação do psiquismo, manifestas através de categorias psicológicas emergentes relacionadas com o modo de vida desenvolvido nesse contexto e com potenciais de reação às condições ultrajantes às quais os sujeitos pobres 
estão expostos. São manifestações "da dimensão subjetiva da vida em condições, que pode interferir nas ações empreendidas pelos sujeitos no curso de suas vidas, nos ideais que elaboram sobre si e sobre o mundo" (Ximenes, Cidade, Nepomuceno \& Leite, 2014, p. 90).

No cenário rural, a dependência da chuva e sua consideração como fenômeno incontrolável, que está à mercê da vontade divina, assim como sua percepção como fenômeno atemporal e ahistórico se somam, então, a necessidade de modificação de planos ou projetos, aos altos índices de perdas da produção agrícola, a falta de água para o consumo humano e consumo animal e às experiências de insegurança quanto a projetos futuros. São condições objetivas sobre as quais se ancoram a análise dos impactos psicológicos da seca na zona rural: a submissão, a resignação e o fatalismo.

A Síndrome Fatalista ou Fatalismo designa, assim como apontado por Martín-Baró (1998), categoria psicológica associada ao modo de funcionar do psiquismo onde o presente e o futuro são percebidos como pré-determinados, fazendo com que os sujeitos aceitem os acontecimentos passivamente, sem questionamentos ou inquietações. A compreensão do cotidiano como fruto da manifestação de forças sobrenaturais ou da vontade divina, impõe o desenvolvimento de ideias, comportamentos e sentimentos que possam dar conta das situações de desesperança e insegurança vivenciadas pelos sujeitos em condições de pobreza e em situações extremas como aquelas geradas pela vivência constante da seca. A "controlabilidade limitada dos perigos" (Blanco \& Diaz, 2007, p. 553) vivida pelas sociedades atuais, mas que se acentuam junto aos povos vulneráveis às mudanças climáticas, contribui para que se estabeleça uma sensação de constante insegurança pessoal e social. Conforme afirma Martín-Baró (1998), a insegurança está relacionada às próprias crenças, ao próprio julgamento, aos sentimentos que experimentam, ao que é bom ou mal, ao que pode e deve fazer e ao que não pode nem deve fazer.
Com isso, tem-se que os sentimentos de tristeza e desânimo decorrentes da experiência da seca podem ser associados ao fenômeno da desesperança aprendida (Ardila, 1979), que se manifesta diante dos investimentos frustrados em mudar a realidade. A situação de desesperança se instaura quando os resultados obtidos não correspondem às ações realizadas, quer dizer, há um alto investimento com vistas a uma mudança positiva da realidade, mas este potencial transformador não se efetiva no cotidiano dos sujeitos.

A repetição de situações de frustração diante dos intuitos não alcançados contribui para o desenvolvimento de uma síndrome psicológica que se manifesta por uma tendência à passividade, perda da motivação, desenvolvimento de respostas comportamentais rígidas e manifestação de sintomas emocionais como medo e depressão (Rodriguez, 2009). Nas comunidades rurais, a instabilidade climática decorrente da seca, aliada ao acesso precário das ações assistenciais corroboram com este sentimento de desesperança quando os sujeitos observam, na concretude do cotidiano, a alimentação precária, a baixa produtividade agrícola, os rendimentos financeiros restritos e os adoecimentos recorrentes.

A naturalização dos fenômenos da pobreza e da seca faz com que os sujeitos justifiquem as incongruências sociais e aceitem passivamente seu destino da forma como conhecem a sua realidade, a mesma de seus antepassados e, por isso, dos seus posteriores. Com isso decorre que não se trata de propor uma análise patologizante ou imóvel da vida em situação de seca. Ao contrário, afirma-se a necessidade de atentar para os riscos subjetivos e os efeitos psicossociais danosos que subjazem ao cotidiano de privações nos contextos rurais marcados pela seca. Afinal, a seca acarreta prejuízos subjetivos no bem-estar e na saúde psicológica dos sujeitos (Favero, 2012).

Porém, um novo cenário no contexto de seca surge a partir da informação de que $60.9 \%$ afirmaram a não saída do campo para a cidade, sendo 
esse fato relacionado com políticas de transferência de renda, tais como: o Bolsa Família e o Auxílio Safra, e benefícios da Previdência Social, como aposentadorias, pensões e auxílios temporários. Lui e Molina (2013) afirmam que a capacidade de consumo das famílias em decorrência desses benefícios e pensões favoreceram o surgimento de outras atividades não-agrícolas nos modos de vida da população rural brasileira. Os prejuízos acarretados pela seca na produção agrícola também estimulam a busca por outras fontes de renda e a ampliação da diversidade de atividades produtivas, como comércio e prestação de serviços.

No que se refere aos $86.9 \%$ da amostra que afirmam não ter retirado que não retiraram nenhum membro da família da escola, constatou-se que esse fato está vinculado com as condicionalidades relacionadas com a obrigatoriedade da permanência das crianças e jovens na escola devido ao Programa Bolsa Família. Nas pesquisas de Brandão, Pereira e Dalt (2013) no Nordeste, os diretores e professores de escolas públicas relacionaram de forma positiva os efeitos do PBF na frequência escolar. Este dado permite, ainda, observar a educação escolar como contexto formativo que tem se estendido por um maior período de tempo na vida dessas crianças e jovens, o que reforçará a possibilidade de desenvolvimento dos novos caminhos de produção anteriormente mencionados.

Considerando o exposto, conclui-se que as variações climáticas serão mais danosas na vida das populações rurais que já se encontram em situações de vulnerabilidade, sendo esta vulnerabilidade não somente às mudanças climáticas, mas também aos fatores sociais. Assim, as ações estatais configuram-se como forças protetivas na busca pela diminuição dos agravos decorrentes da seca, além de ser também de sua responsabilidade o incentivo à ações de participação popular e controle social no sentido de favorecer a recuperação da memória coletiva dos povos que convivem historicamente com a seca.

\section{Conclusão}

A seca é um fenômeno de mudança climática extrema que ocorre secularmente no nordeste brasileiro. Porém, este fenômeno não pode ser naturalizado em suas decorrências objetivas e subjetivas, isto é, naquilo que implica economicamente, socialmente, politicamente e também no cotidiano e na saúde da população. Percebe-se que é necessária a contextualização histórica, política e social deste fenômeno considerado por muito tempo como estritamente natural, mas que gerou e ainda gera na população rural nordestina diversas implicações materiais e psicológicas, sendo mantido, muitas vezes, por interesses da chamada Indústria da Seca.

Dentre os principais impactos psicossociais analisados nesse estudo, destacam-se a insegurança quanto ao futuro, sentimentos de desânimo e tristeza. A insegurança cotidiana vem implicar em mecanismos psíquicos de proteção para o bem-estar dos sujeitos, o que se manifesta no fatalismo e na desesperança aprendida. No aspecto de mudanças da realidade construídas e dos mitos relacionados ao cenário da seca, como a migração, o flagelo, a miséria, foram encontrados dados que demonstram a não migração do campo para a cidade e nem a saída da escola de algum membro da família, relacionados à presença de programas de assistência e previdência social que aos poucos modificam o cenário de convivência com a seca, sendo ainda insuficientes para garantir o bem estar social e a diminuição das desigualdades.

É possível viver e conviver com o Semiárido nordestino desde que existam novas políticas públicas que enfatizem o desenvolvimento das potencialidades individuais, coletivas e comunitárias, bem como, com práticas sustentáveis e coerentes com as necessidades e possibilidades locais. $\mathrm{O}$ papel do Estado é fundamental para implementar novas políticas públicas de convivência com a seca e garantir os direitos sociais. 


\section{Referências}

Alkire, S. (2005). Why the capability approach? Journal of Human Development, 6(1), 115-134.

Andrade, M. C. (1985). A seca: realidade e mito. Recife: Asa.

Ardila, R. (1979). Psicología social de la pobreza. Em J. Whittaker, Psicología social en el mundo de hoy (pp. 399-418). México: Trillas.

Banco Mundial. (2001). Combate à pobreza rural no Brasil: uma estratégia integrada (vol. 1). (Relatório n ${ }^{\circ}$ 21790-BR). Tomado de: http://siteresources.worldbank.org/BRAZILINPOREXTN/ Resources/3817166-1185895645304/40441681186331278301/05PobrezaRuralVol1.pdf

Blanco, A. \& Diaz, D. (2007). El rostro bifronte del fatalismo: fatalismo colectivista y fatalismo individualista. Psicothema, 19(4), 552-558.

Brandão, A., Pereira, R. de C., \& Dalt, S. da. (2013). Programa Bolsa Família: percepções no cotidiano da escola. Revista de Ciências Sociais, $38,215-232$.

Brasil. (2011). Institui o Plano Brasil sem Miséria. Decreto No. 7.492, de 2 de junho de 2011. Recuperado de http://www.planalto.gov.br/ccivil_03/_ Ato2011-2014/2011/Decreto/D7492.htm

Brasil. (2013). Observatório de Enfrentamento à Seca. Recuperado de: http://www.brasil.gov. br/observatoriodaseca/index.html

Bruna, G.C. \& Pisani, M.A.J. (2010). Mudanças climáticas e pobreza: reflexões. Revista Brasileira de Ciências Ambientais, 18, 58-66. Recuperado de http://www.rbciamb.com.br/images/online/RBCIAMB-N18-Dez-2010-Materia06_artigos261.pdf

Carvalho, O. (1988). A economia política do Nordeste (seca, irrigação e desenvolvimento). Rio de Janeiro, Brasília: Campus, ABID.

Carvalho, O. (2012). As secas e seus impactos. Em Brasil, Centro de Gestão e Estudos Estratégicos, A questão da água no nordeste / Centro de Gestão e Estudos Estratégicos, Agência Nacional de Águas. Brasília: CGEE.
Castro, I. E. (1992). O mito da necessidade: discurso e prática do regionalismo nordestino. Rio de Janeiro: Bertrand Brasil.

Castro, J. (1967). Sete palmos de terra e um caixão: ensaio sobre o Nordeste, área explosiva (2a ed.). São Paulo: Brasiliense.

Cidade, E. C., Moura Junior, J. F. \& Ximenes, V.M. (2012). Implicações psicológicas da pobreza na vida do povo latino-americano. Psicologia Argumento, 30(68), 87-98.

Cirilo, J. A., Montenegro, S. M. G. L., \& Campos, J. N. B. (2007). A questão da água no semiárido brasileiro. Recuperado de http://www.abc.org. br/IMG/pdf/doc-811.pdf

Duarte, R. (1999). A seca nordestinha de 1998-1999: da crise econômica a calamidade social. Recife: Sudene.

Duarte, G.B.; Sampaio, B. \& Sampaio, Y. (2009). Programa Bolsa Família: impacto das transferências sobre os gastos com alimentos em famílias rurais. Revista de Economia e Sociologia Rural, 47(4), 903-918.

Echeverría, R.G. (1998). Estrategia para la reducción de la pobreza rural. Washington, D.C.: Banco Interamericano de Desarrollo, Departamento de Desarrollo Sostenible.

Favero, E. (2012). O impacto psicossocial das secas em agricultores familiares do Rio Grande do Sul: um estudo na perspectiva da psicologia dos desastres (tese de doutorado). Programa de Pós-graduação em Psicologia, Universidade Federal do Rio Grande do Sul, Porto Alegre. Recuperado de http://www.lume.ufrgs.br/bitstream/handle/10183/55063/000856224.pdf?sequence=1

Góis, C. (2008). Saúde comunitária: pensar e fazer. São Paulo: Editora Hucitec.

Gomes, M.C. (2010). Canafístula: vida e esperança no sertão nordestino. Estudo sobre a experiência de desenvolvimento local na organização socioeconômica do povoado de Canafistula, Apuiarés/ $C E$ (dissertação de Mestrado Acadêmico em Políticas públicas e Sociedade), Universidade Estadual do Ceará, Fortaleza. Recuperado de 
http://www.uece.br/politicasuece/index.php/ arquivos/doc_view/127-meirijanecardosogomes?tmpl=component\&format $=$ raw

Instituto Brasileiro de Geografia e Estatística (IBGE). (2011). Censo demográfico 2010. Brasília: Ministério do Planejamento, Orçamento e Gestão.

Leite, J.F., Macedo, J.P.S., Dimenstein, M. \& Dantas, C. (2013). A formação em psicologia para a atuação em contextos rurais. Em J.F. Leite \& M. Dimenstein (Org), Psicologia e contextos rurais (pp. 17-56.) Natal: EDUFRN.

Lui, G. H. \& Molina, S. M. G. (2013). Benefícios sociais e transição de modos de vida rurais: uma análise do Bolsa Família e da aposentadoria rural entre pequenos produtores na Amazônia. Revista de Ciências Sociais, 38, 137-155.

Marinho, E.; Linhares, F. \& Campelo, G. (2011). Os programas de transferência de renda do governo impactam a pobreza no Brasil? Revista Brasileira de Economia, 65(3), 267-288.

Martín-Baró, I. (1998). Psicología de la liberación. Madrid: Trotta.

Matos, M.P.S.R. (2012). Famílias desagregadas sobre a terra ressequida: industria da seca e o deslocamentos familiares no Nordeste do Brasil. Nómadas-Revista Crítica de Ciencias Sociales y Jurídicas (especial: América Latina). Recuperado de http://dssbr.org/site/2013/05/desigualdades-relacionadas-a-distribuicao-de-agua-no-nordeste/

Mocelin, C. E. (2011). Pobreza rural e o programa bolsa família: o caso da comunidade de São João do Barro Preto Júlio de Castilhos (RS) (dissertação de Mestrado em Extensão Rural), Universidade Federal de Santa Maria, Santa Maria.

Nobre, M. C. de Q. (2010). Cercas e secas na história do Ceará: expressões da "questão social". Documento procedente de XII Encontro Nacional

\section{Data de recepção: 13 de janeiro de 2015 Data de aceitação: 19 de agosto de 2015}

de Pesquisadores em Serviço Social, 6 a 10 de dezembro.

Organização das Nações Unidas no Brasil. (2013). Pior seca dos últimos 50 anos no nordeste brasileiro confirma estatísticas da ONU sobre escassez. Recuperado de http://www.onu.org. br/pior-seca-dos-ultimos-50-anos-no-nordeste-brasileiro-confirma-estatisticas-da-onu-sobre-escassez/

Queiroz, R. de. (2008). O quinze. (85a ed.). Rio de Janeiro: José Olympio.

Ribeiro, W.R. (1999). Seca e determinismo: a gênese do discurso do semiárido nordestino. Anuário do Instituto de Geociências, 22, 60-91.

Rodríguez, F. (2009). Entre la clínica y la cultura: psicoterapia con pacientes en condiciones de pobreza y exclusión. Em A.E.H. Gómez (Coord.), Sujetos políticos y acción comunitaria: claves para una praxis de la psicología social y de la clínica social-comunitaria en América Latina (pp. 269-300). Medellín: UPB.

Santos, E., Matos, H., Alvarenga, J., \& Sales, M.C.L. (2012). A seca no Nordeste no ano de 2012: Relato sobre a estiagem na região Nordeste e o exemplo de prática de convivência com o semiárido no Distrito de Iguaçu/Canindé/Ce. Revista Geonorte, Edição Especial 2, 1(5), 819-830.

Sen, A. (2000). Desenvolvimento como liberdade. São Paulo: Companhia das Letras.

Vieira JR., A.O. (2003). O açoite da seca: família e migração no Ceará (1780-1850). Boletim de História Demográfica, 27. Recuperado de http://www.abep.nepo.unicamp.br/docs/anais/ pdf/2002/GT_His_ST4_Vieira_texto.pdf

Vygotsky, L. S. (1991). A formação social da mente. São Paulo: Martins Fontes.

Ximenes, V.M., Cidade, E.C., Nepomuceno, B.B., \& Leite, J.F. (2014). Pesquisa e intervenção a partir da realidade social: desvelar das implicações psicossociais da pobreza. Em C. Stella (Org.), Psicologia comunitária: contribuições teóricas, encontros e experiência (pp. 87-110). Petrópolis: Vozes. 